\title{
UNA HUELLA MEXICANA EN EL CINE ESPAÑOL: LA NATURALEZA MÁGICA Y RESISTENTE EN BIUTIFUL DE ALEJANDRO GONZÁLEZ IÑÁRRITU Y EL LABERINTO DEL FAUNO DE GUILLERMO DEL TORO
}

\section{MEXICAN FOOTPRINTS IN SPANISH FILM: MAGICAL AND RESISTENT NATURE IN ALEJANDRO GONZÁLEZ IÑÁRRITU'S BEAUTIFUL AND GUILLERMO DEL TORO'S PAN'S LABERINTH}

\author{
David Dalton \\ Pittsburg State University
}

\begin{abstract}
RESUMEN
Guillermo del Toro y Alejandro González Iñárritu son de los protagonistas más conocidos del movimiento transnacional en los cines mexicanos e hispanos del nuevo siglo. Sus éxitos tanto en su país de origen como en España y Estados Unidos atestiguan de sus habilidades y su visión. El presente estudio descubre una estética latinoamericana y mexicana acerca del papel de la naturaleza y el paisaje nacional que aparece en su cine español.
\end{abstract}

Palabras clave: Guillermo del Toro, Alejandro González Iñárritu, cine español, la naturaleza y el paisaje nacional.

\begin{abstract}
Guillermo del Toro and Alejandro González Iñárritu sit at the fore of the transnational shift in Mexican and Hispanic cinemas of the new century. Their successful films both at home and in Spain and the US have attested to their skill as auteurs and visionaries. The present study uncovers the Latin American and Mexican aesthetics surrounding the role of nature and the national landscape in these directors' Iberian films.
\end{abstract}

Keywords: Guillermo del Toro, Alejandro González Iñárritu, Spanish film, the role of nature and the national landscape. 
La primera década del siglo veintiuno marcó una mayor colaboración entre las industrias fílmicas latinoamericanas y españolas'. Pocos directores encontraron mayor éxito en este nuevo ámbito que los mexicanos Guillermo del Toro y Alejandro González Iñárritu, quienes tocaron temas españoles con una sofisticación casi sin igual en sus filmes El laberinto del fauno (del Toro 2006) y Biutiful (González Iñárritu 2010)². Para el espectador no iniciado estas películas parecen ejemplos especialmente bien hechos del cine español, y el hecho que sus directores sean mexicanos parece coincidencia. No obstante, ambas películas representaron a México en los Óscars, un hecho que sugiere una estética mexicana en ambos filmes (CHÁVEZ 398-99/3. Aunque tengan poco en común, estas dos películas tratan temas que ligan la experiencia mexicana a la española: la Guerra Civil Española en El laberinto - ningún país aceptó a más refugiados republicanos que México ${ }^{4}$ - y la migración en la época neoliberal en Biutiful. Del Toro y González Iñárritu recurren a imaginarios latinoamericanos en su cine y postulan una naturaleza mágica y resistente que sirve como un escape del mundo opresivo. Al invocar estos discursos transnacionales, del Toro y González Iñárritu convierten temas supuestamente locales en universales.

La mayoría de la crítica sobre estos directores ignora su nacionalidad. Según Ignacio M. Sánchez Prado, "such omissions result in major misreadings and misunderstandings of their work, by inscribing them into cul-

1 Pedro Almodóvar y su hermano expandieron su compañía de producción a América Latina en 2001 (Tierney 168). Según Francisco J. Sánchez, películas como El laberinto operan en un modo de producción que "displaces the political context of the nation of Spain into a trans-Atlantic Spanish region in which Spanish functions as a Brand of cultural goods" (142-45).

2 El éxito de estos dos directores no se limita al contexto español; también han producido películas de renombre en México y Estados Unidos. Véanse Deborah Shaw (1-6) y Christina L. Sisk (163-81).

3 Daniel Chávez postula a del Toro como "epítome de la nueva era transnacional en la producción del cine mexicano e iberoamericano" (371); lo mismo puede decirse de González Iñárritu.

4 Del Toro reconoce que su propia experiencia con refugiados republicanos en México afecta como se acercó a este filme (Camino 50). 
tural dynamics - from Spanish postdictatorial culture in the case of del Toro to Sundance-style independent cinema trends in the case of González Iñáritu - where they, at best, fit awkwardly" (Screening). Sánchez Prado enfatiza los factores del cine nacional mexicano en pos de la aprobación del Tratado de Libre Comercios (1994) - tales como la liberalización de producción y el enfoque de dirigir películas a las clases medias y medio altas - como clave en entender a estos directores. Limita su enfoque a sus filmes mexicanos en su libro, pero reconoce la necesidad por otros estudios sobre "the underlying Mexican processes that [define] their cinema" (Screening). Estas aseveraciones no significan que no haya habido influencias recíprocas entre estos directores y la industria española; esto es especialmente visible en el caso de Guillermo del Toro, quien, como observan Dolores Tierney, Deborah A. Shaw y Ann Davies, ha reinvigorado la industria

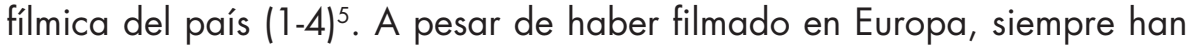
quedado en su cine rastros de su posición subjetiva como mexicano y latinoamericano (CHÁVEZ 372); hablando de su filme El espinazo del diablo (2001), por ejemplo, Isabel Santaolalla asevera "un conjunto de elementos extranjeros como forma de ofrecer una perspectiva distanciada de la realidad de España" (222), una observación que se aplica a ambos filmes que trataremos aquí. Además de producir una multiplicidad de voces, estos directores evocan a las grandes narrativas latinoamericanas del paisaje viviente que empezaron con la llegada de Colón a América (RIVERA-BARNES Y HOEG 10-24).

Estas cintas exaltan las tierras (y, en el caso de Biutiful las aguas) vírgenes españolas, pintándolas como los últimos refugios de una máquina opresora nacional. Los directores mexicanos invierten la lógica de los conquistadores - quienes históricamente llegaron a América y aseveraban una naturaleza edénica para justificar sus incursiones en la tierra (RIVERA-BARNES Y HOEG 12) - y en vez de fantasear una dominación de la ecología española, la exaltan como un espacio adonde todavía no llega la corrupción del "progreso" industrial, político ni económico. Del Toro y González Iñárritu representan tanto el fascismo como el capitalismo democrático como discursos opresivos cuyos efectos pueden ser fatales, y ambos imaginan el retorno a la naturaleza como la única manera de liberarse de las estructuras opresivas de poder. A pesar de su discurso resistente, estas películas no son precisamente progresistas, pues su evocación de lo natural tiende a favorecer lo tradicional. Beatriz Rivera-Barnes y Jerry Hoeg

5 Según Shaw, El laberinto es una película europea paradigmática por su "shift away from rigid boundaries of art cinema, while retaining some of its characteristics, to create a form of cinema which has resulted in increased global consumption" (73). 
enfatizan que cuando teorizamos la naturaleza debemos tomar en cuenta que "nature includes human nature" (2). Esta observación ayuda a aclarar el fascinante tratamiento que recibe la unidad familiar en ambas películas, pues las dos la conciben como vía "natural" para propagar y mejorar la especie humana. Es más, postulan que la fragmentación de la familia heterosexual y patriarcal produce una sociedad corrupta con tendencias opresivas.

Visto de esta manera, el retorno a la naturaleza, además de señalar el rechazo de los discursos opresivos, conlleva una restauración de la unidad familiar tradicional. La promesa de vivir con un padre y una madre verdaderos motiva a Ofelia, la niña protagonista de El laberinto, a explorar el mundo mágico del fauno ${ }^{6}$. Es así que Ofelia embarca a una búsqueda en un mundo de hadas que paralela el de la España fascista de 19447, y en sus desafíos ella tiene que defender y depender de la naturaleza. Además de evocar los tropos de cuentos de hadas de una madrastra malvada padrastro en este caso (Tierney 174; Lukasiewicz 73; Hanley 37) - la relación antagonista entre Ofelia y el capitán refleja el hecho que ambos quieren solidificar su relación con Carmen y el bebé por nacer a la exclusión del otro ${ }^{8}$. Algo parecido sucede en Biutiful donde, según Anna Casas, "la paternidad tradicional [. . .] se presenta como fundamento social que se tambalea en el contexto neoliberal globalizado" (180). Uxbal, el protagonista, nunca conoció a su propio padre ya que éste tuvo que huir a México antes que él naciera por sus ideas anti-franquistas. Como tal, Uxbal se dedica a ser un buen padre, lo cual lo señala como personaje moral dentro de los paradigmas ideológicos del cine de González Iñárritu a pesar de sus acciones ilícitas (Sánchez Prado, "Amores perros" 40). La naturaleza en este filme representa el único lugar en que una familia puede estar unida, pero la presencia sofocante de la jungla urbana imposibilita tal escape.

Ambos directores ligan lo natural a la magia, pero sus representaciones de lo sobrenatural varían grandemente. Inspirado por los cuentos de hadas

6 Viendo la tensión entre Ofelia y Vidal, Jennifer Orme arguye que El laberinto critica las formas patriarcales de liderar la familia y la nación (223). Diferimos con ella porque, al regresar con su padre el rey simplemente suple un patriarca por otro. La película enfatiza el trauma que el patriarcado puede causar no sólo en las mujeres sino también en los hombres, pues como arguye Francisco J. Sánchez, la maldad del capitán Vidal se basa en la presión que siente de seguir el ejemplo de su padre, quien murió en la guerra (138-42).

7 Lejos de ser una alternativa al mundo real, este mundo fantástico es mórbido. Véanse Tierney (175) y Hubner (55).

8 Laura Hubner nota una parte clave del antagonismo entre Vidal y Ofelia al aseverar que "evil lies outside Ofelia's natural bloodline" (53), pues su padre verdadero era republicano. 
de los Hermanos Grimm entre otros (Ramos; Chávez 400), del Toro dirige una película en que el mundo fantástico de la niña Ofelia y el mundo real y tecnológico del capitán avanzan paralelamente y su única convergencia se centra en el personaje de Ofelia9. En Biutiful, Uxbal, además de trabajar en las economías clandestinas del contrabando y la inmigración indocumentada, puede comunicarse con los muertos, lo cual lo señala como "intermediario ilícito" (Giunini 219). Al principio del filme dos padres le piden que hable con su hijo muerto y que le ayude en su transición al mundo venidero. Este toque mágico en lo que de otra forma sería un filme realista ancla Biutiful firmemente en la tradición del realismo mágico, lo cual sugiere una estética latinoamericana en vez de peninsular. Lois Parkinson Zamora y Wendy B. Faris aseveran que en el realismo mágico, "the supernatural is not a simple or obvious matter, but it is an ordinary matter, an everyday occurrence-admitted, accepted, and integrated into the rationality and materiality of literary [or filmic] realism" (3). Esta explicación se aplica perfectamente a Biutiful, donde los personajes entienden las visiones de Uxbal como una parte normal (aunque fantástica) de la vida. El realismo mágico latinoamericano mayormente se basa en las cosmovisiones indígenas y afrolatinas, o más estrechamente, en tradiciones no occidentales (Zamora y Faris 3-5). Esta articulación desde la periferia impregna los discursos mágicos reales con una calidad resistente, pues invalidan las ideologías occidentales y hegemónicas. González lñárritu establece varios indicadores que sitúan a Uxbal como extranjero, pues implica una posible ascendencia moro y/o sefardí por el actor marrueco-español, Nasser Saleh Ibrahim, que interpreta a su padre (Difrancesco 32; del Mar Azcona 8), y su nombre alude a una posible conexión a las culturas vascas y/o mayas (Hing-Yuk Wong 13).

La magia nunca logra una cotidianidad semejante en El laberinto, pues se ubica dentro del marco de los cuentos de hadas cuyas referencias a la magia se articulan en paradigmas de fantasía occidentales. Según Tracie D. Lukasiewicz, el filme es una obra neorreal mágica, una tradición que ella distingue sofisticadamente del realismo mágico, pues en el neorrealismo mágico lo fantástico nunca llega a ser cotidiano (64-67; Véase también Thormann 176). A pesar de su acertada defensa del término, coincidimos con Jane Hanley, quien lee el filme como un cuento de hadas en que la separación rígida de lo real y lo fantástico produce la tensión necesaria

9 William O. Deaver Jr. arguye que estos mundos se paralelan "como los círculos concéntricos de la escalera de caracol que conduce al laberinto" (159). 
para articular y conmemorar el trauma nacional (36-38) ${ }^{10}$. Ciertamente, el intento de leer el filme como obra (neo)real mágica nos parece forzado y dudamos que el filme se leería así si su director no fuera mexicano ni latinoamericano. A fin de cuentas, esta discusión semántica tiene poca importancia en nuestros análisis, pues la crítica está unida en aseverar una distinción rígida entre el mundo fantástico y el mundo real en este filme. Del Toro cinematográficamente distingue estos mundos a través de un juego de colores oposicionales; el mundo real tiene muchos grises, azules y verdes mientras que el mundo fantástico goza de mucho oro, ámbar y rojo (Vargas 190; Gómez-Castellano 11; O’Flynn; Shaw 74). En Biutiful, González Iñárritu captura las visiones de Uxbal con tomas de ángulo contrapicado para enfatizar que el mundo de los espíritus existe en un plano mayor, pero los colores que asocia con dicho mundo se parecen a los del resto de la película. Ciertamente, cambia a un lente anamórfico al final del filme para representar la convergencia del mundo fantástico -el de los muertoscon el mundo urbano (del Mar Azcona 10). A diferencia de El laberinto el filme de González Iñárritu niega una línea estricta entre el mundo real y el fantástico.

Ya hemos establecido que ambos directores recurren a estrategias distintas para articular la magia; no obstante, ambos convergen en yuxtaponer lo sobrenatural con la naturaleza. Cada representación de la ecología en Biutiful tiene una conexión directa con las visiones (¿alucinaciones?) mágicas reales que tiene Uxbal, pero la audiencia tiende a ignorar este hecho ya que el director fusiona el mundo "real" con el fantástico de una manera tan sofisticada que no reconocemos cómo la magia - sobre todo en la forma de la naturaleza - afecte la Barcelona cotidiana. A fin de cuentas, el discurso de una ecología mágica real sólo puede ser resistente si subvierte una forma de opresión vinculada a la ciudad. Como tal, tomamos como punto de partida el estudio de Benjamin Fraser, quien analiza los elementos formales del filme desde la perspectiva de los estudios urbanos, con su tensión entre la ciudad vivida y la ciudad arquitectural y turística (21-22). Su enfoque en el espacio vivido destaca la deshumanización que enfrentan los inmigrantes indocumentados de la ciudad y cuestiona los discursos hegemónicos que posicionan a Barcelona como un ejemplo por excelencia de la ciudad moderna europea, algo que se nota por la carencia casi completa de sitios turísticos famosos en la cinta (24). Extendemos los argumentos de Fraser y proponemos que, además de criticar las opresiones inherentes a

10 Cristina Carrasco arguye que del Toro subvierte varios tropos de los cuentos de hadas, así creando una manera en que se puede mostrar y enmendar la violencia de la Guerra Civil Española (16). 
la vida urbana del siglo XXI, González Iñárritu imagina un escape de esta vida deshumanizadora en el mar y el paisaje vírgenes; no obstante, este potencial queda efímero.

El filme comienza y termina con una escena en que el moribundo protagonista habla con su hija. De repente la cámara corta a una escena en un bosque invernal y Uxbal dice, "tu madre nunca escuchó [. . . ] el ruido del mar. Cuando yo era pequeño había una estación del radio que ponía los sonidos del mar. Se escuchaban sus olas gigantes. Su sonido me daba miedo". Su terror del mar señala que lo natural - no lo urbano- ya le es alienígeno, pero este mismo sentimiento revela un potencial redentor que existe fuera de la ciudad. Esta escena también alude al hecho que la ciudad reserva sus sitios más conocidos (la playa, por ejemplo) para agentes del capital extranjero, sobre todo los negociantes y turistas internacionales (Fraser 26-28). Lo que parecieran ser las incoherencias de un hombre al punto de morir toma un aspecto mágico real cuando Uxbal de repente encuentra a su padre, quien le afirma que "aquí antes no había nada; sólo agua salada." Al yuxtaponer la muerte, la naturaleza y la restauración de los vínculos entre padre e hijo, esta escena establece la base discursiva del filme. Irónicamente, estas tomas del protagonista cuando está a punto de morir lo retratan más vivo y sonriente que en cualquier otro momento del filme. Esto puede ser en parte porque, como observa Lorenzo J. Torres-Hortelano, el padre de Uxbal "le muestra un camino más allá, en el fuera del campo" (66), lo cual sugiere que la naturaleza provee un escape del mundo deshumanizador y urbano. María DiFrancesco señala que esta escena "allows us to read the landscape as an area where there is a volatile collapse of limits between the living and the dead" (35). Además de punto liminal entre vida y muerte, el paisaje evoca a una Barcelona fantasmal: el paisaje que existía antes de la urbanización.

Esta escena tiene lugar en los pirineos - montañas que sirvieron como ruta de escape para los exiliados republicanos durante el franquismo (DiFrancesco 31). En este filme estas montañas retienen su valor resistente, pero su contexto es ahora el estado democrático y neoliberal español. Las montañas evocan la presencia fantasmogórica del paisaje en el espacio que hoy en día es una de las ciudades europeas más importantes. Durante la mayor parte del largometraje, el paisaje existe como apenas un recuerdo de lo que hubo antes de la modernización. González Iñárritu enfatiza este hecho cuando corta de la escena brillante en el monte a una escena en una oficina médica oscura y luego a otra en la estación oscura de metro. Estas imágenes destacan la deshumanización abrumadora del mundo urbano, sobre todo para personas como Uxbal y los migrantes que trabajan con él. Varios críticos han señalado los lazos que vinculan 
a Uxbal y los inmigrantes (tanto senegalenses como chinos), pues aunque él nació en Barcelona, su familia probablemente inmigró de Andalucía a Barcelona, y su padre tuvo que emigrar a México, aunque pronto murió de pulmonía (del Mar Azcona 3-12; Difrancesco 26-27). Además de estas conexiones, aseveramos que Uxbal y los migrantes están implicados en varias tomas irónicas que ligan la contaminación tanto ecológica como societaria a la migración. Hablando de la inmigración en Estados Unidos, J. David Cisneros arguye que los medios de comunicación, sobre todo las noticias de cablevisión, usan las mismas técnicas fílmicas para reportar amenazas ecológicas como para representar a la población migrante en el país (578-83). Claro está que Cisneros habla del contexto norteamericano, pero como González Iñárritu es un ciudadano mexicano viviendo en California, dichos discursos han influido cómo entiende la cuestión migratoria en España (Deveny, Migration 128) ${ }^{11}$.

El discurso de contaminación sobresale en las tomas de los inmigrantes chinos durante toda la película. Trabajan largas horas en algunas maquiladoras pertenecientes a Hai, un hombre chino de negocios, y viven en una bodega adjunta. El director yuxtapone tomas de los trabajadores con contrapicados de la chimenea de la fábrica mientras eructa humo. Esta imagen seguramente intencional captura el barrio Poligono Sur, donde hay muchas fábricas en manos chinas (Begin 5-6; Deleyto y López 171). El contaminante más repugnante según el filme no es ni el humo ni la presencia de cuerpos extranjeros en la ciudad, sino cómo los demás se aprovechan de éstos. Según Paul Begin, los personajes de Hai y su socio Liwei evocan el imaginario del empresario chino corrupto que trata tanto al ser humano como a la ecología como recursos que explotar (11). Esto se ve claramente cuando Uxbal y los empresarios consiguen a los inmigrantes indocumentados trabajos en la construcción, dividiendo la mayoría de las ganancias de los trabajadores entre ellos. Una toma de ángulo picado de una retroexcavadora rascando la tierra coincida con su primer día de trabajo. Además de criticar la deshumanización de los migrantes, esta imagen atestigua las heridas que se le han tenido que hacer al paisaje para construir esta ciudad moderna. Su yuxtaposición con los trabajadores chinos asevera una mutua explotación entre la tierra y los obreros internacionales, lo cual afirma que la contaminación no viene de afuera, sino de por dentro. Este hecho se ve especialmente claro en una escena donde los trabajadores mueren asfixiados cuando Uxbal les compra calentadores defectuosos de

11 Del Mar Azcona dialoga mucho con pensadores chicanos - sobre todo Gloria Anzaldúa y Guillermo Gómez Peña- para teorizar las fronteras en Biutiful. 
gas. Cuando se entera de lo sucedido, Uxbal entra a la bodega y llora; varios contrapicados capturan los espíritus de los muertos como si estuviesen flotando acostados en el techo. Esta escena es bastante mágica real; Uxbal ve los fantasmas, los menciona y les habla, pero esta presencia no irrumpe la trama.

El aspecto mágico real se extiende a cómo estos muertos interactúan con la naturaleza. Como no hay registros oficiales de los trabajadores muertos en España, Liwei supone que al desaparecer los cuerpos, Hai y él podrán evitar a las autoridades. Su preocupación no es por los muertos (ni sus familias) en sí, sino cómo esto afectará su negocio. Decide arrebatarlos al mar, pensando que de esta manera nadie se enterará, pero las noticias reportan que las aguas han regresado estos cadáveres a la playa. Hai le dice a Uxbal que Liwei actuó sin consultarlo, pero también reporta que su socio se cercioró que se hundieron. El hecho que el mar divulga esta evidencia alude a una alianza entre el marginado y el mar, algo que González Iñárritu ha aseverado en varias entrevistas (Deleyto y del Mar Azcona 139). Este acontecimiento representa una instancia de realismo mágico en que el mar defiende su relación con los extranjeros que viven en la periferia. Esta escena encapsula mejor que tal vez cualquier otra las instancias en que surgen los discursos mágicos reales del filme, pues la apariencia de los cadáveres nuevamente a la tierra toca temas como la muerte, la redención y la naturaleza. El intento de Liwei de borrar las vidas de sus trabajadores representa un intento de contaminar a la misma naturaleza con sus actos viles. Aquí la naturaleza misma se rebela, y el mar escupe a las víctimas a pesar de las precauciones de Liwei. Sería difícil comprobar que el mar tenga vida en el filme; más bien aseveramos que hay un poder que opera en el filme que utiliza la ecología, el paisaje y sobre todo el mar para resistir los efectos deshumanizadores de la esfera urbana y condenar a los negociantes explotadores.

Además de ser capitalistas corruptos, Hai y Liwei mantienen una relación homosexual que sirve como metáfora conservadora de su decadencia (Begin 10-11; Casas Aguilar 184). Hai sólo puede iniciar su camino redentor al matar a su amante. Yuxtapuesto con un discurso supuestamente naturalista que exalta la unidad familiar heterosexual - la cual viola Hai al serle infiel a su esposa y llevar una relación homosexual con Liwei- este asesinato pone los medios para que él regrese con su familia nuclear. Como arguye Anna Casas Aguilar, "la historia de Hai es una macabra contra de Uxbal, que beneficia al protagonista al contrastarlo con aquellos padres más despiadados y codiciosos que él" (184). Ciertamente, es la yuxtaposición de Uxbal con estos personajes que lo pinta de una manera favorable; sólo así puede el filme justificar la redención que goza por su de- 
voción a sus hijos. Debido a sus deseos de cumplir con las construcciones societarias del padre protector (Casas 179), Uxbal le oculta su cáncer de próstata terminal a su familia. El protagonista negocia su incipiente muerte de una manera bastante mágica real, pues visita a una amiga médium que le dice que ponga los fundamentos para que a sus hijos no les haga falta $^{12}$. Conociendo su suerte, busca la manera de conseguirles dinero y de asegurarse que tengan quién los cuide. Primero piensa en Maramba, su esposa separada, alcohólica y bipolar, quien aparentemente ha dejado sus adicciones atrás.

Cuando Uxbal le pregunta cómo los doctores lograron quitarle su adicción, su esposa le contesta que no fue por medicina sino por una caja de luz que se pone todos los días. Aquí Maramba favorece los tratamientos folclóricos a los medicinales, y su aparente remisión -luego vuelve a caer en lo mismo - respalda una visión mágica real del mundo, pues se mejora a pesar de usar una técnica que tiene poca credibilidad científica ni médica. Esta caja de luz también alude a una cualidad asfixiante de lo urbano y el poder restaurativo de lo natural. Maramba afirma que absorbe varias vitaminas de esa luz que no podría obtener de otra manera debido a que se tiene que quedar en casa la mayoría del tiempo. La mejor resolución a su condición sería quedarse fuera de casa -y de preferencia de la ciudad-por mucho tiempo. Ya que ésta no es opción, la caja de luz suple el poder regenerador de la naturaleza. Visto en este contexto, el plan que forman Uxbal y Maramba de llevar a sus hijos a acampar en los pirineos toma más significado. Desean llevarlos a las montañas porque jamás han salido de la ciudad, y su acto de estar en la naturaleza podrá purificarlos. Uxbal tiene que cancelar cuando mueren los trabajadores en la bodega, pero les anima a ir sin él. Al llegar a casa halla a su hijo, quien le explica que no pudo ir por castigado; está acostado al lado de la caja de luz que grotescamente sustituye la nieve que iba a ver. También esta luz descubre un moretón en la mejilla del niño donde su madre le golpeó.

Al ver que Maramba no podrá proveerles a sus hijos una vida estable, Uxbal la expulsa de su casa y busca otra forma de cuidarlos. Terminan quedándose con lge, la esposa de un hombre senegalense que había trabajado para Uxbal y fue deportado por vender narcóticos. González Iñárritu yuxtapone la deterioración de la salud de Uxbal con imágenes mágicas reales que evocan a la naturaleza. Varias tomas desde su perspectiva cap-

12 Hablando de esta y otras películas de González Iñarritu, Juan Orellana Gutiérrez de Terán observa que "el tema de la muerte siempre está catalizado por las relaciones padres-hijos" (1170). 
turan mariposas nocturnas enormes en el techo de su habitación que aluden a obras literarias mágicas reales como Cien años de soledad (1967) de Gabriel García Márquez, donde la presencia de estos insectos denota la muerte. Aquí la representación es más ambigua, pues nunca se sabe a ciencia cierta si el protagonista, como arguye María DiFrancesco (34), alucina por las drogas que toma para controlar el dolor, o si realmente ve un espectro que anuncie su muerte. Además de señalar su próximo fallecimiento, las mariposas representan una invasión silvestre a lo doméstico y urbano, lo cual puede ser - por lo menos dentro del marco del filmepositivo. Estas visiones culminan con la misma conversación que vimos al principio del filme, donde Uxbal se reúne con su padre después de una conversación con su hija. Esta reunión con su familia -sobre todo con el padre que nunca conoció- en un paisaje virgen (¿̇alucinado?) simboliza su última redención.

La búsqueda por un padre perdido - esta vez un rey en un mundo fantástico- sirve como punto de partida en El laberinto también. El discurso mágico gira sobre dos ejes principales: la restauración de la unidad familiar tradicional y la evocación de la ecología. Varios críticos mencionan que la naturaleza sirve como refugio de la opresión del fascismo en el filme (Clark y McDonald 53; Enjuto Rangel; Carrasco 23-24; Hanley 37; Tsuei 232; Thormann 179), pero tienden a dedicarle poca atención a este aspecto del filme. Mercedes Camino asevera el paisaje como un escape "claustrofóbico" de la dictadura (49), algo que se nota por la presencia de los maquis, cuya "association with the scenery of which they became an integral part makes the landscape, especially the mountains, an over-determined sign" (48). Por su parte, Barry Spector asevera que las dos figuras patriarcales que tiene Ofelia evocan a Cronos (Vidal) el devorador de niños (83), y a $\operatorname{Pan}^{13}$, el dios chivo del bosque (81) $)^{14}$. Además de asociar al fauno con los maquis en su guerrilla contra Vidal (Chávez 399), esta observación elucida la aserción de Laura Hubner que "the film's rural setting of dark undergrowth and Woodland helps enable a blurring between

13 Del Toro aclara enfáticamente que el fauno no es Pan; escogió este título en inglés porque se oía mejor que The Labyrinth of the Faun ("Power").

14 Gran parte de su argumento se basa en el título del filme en inglés, Pan's Labyrinth, pues aunque el fauno parece a Pan, no hay evidencia textual en español que lo ligue al dios griego del bosque. Por su lado, Paul Juliàn Smith arguye que la naturaleza que vemos en este filme no es la entidad sensual del Pan de la mitología griega (8). 
'reality' and fantasy" (48) ${ }^{15}$. En esta sección del artículo extendemos la crítica ya mencionada e interpretamos los tres desafíos que enfrenta Ofelia como pruebas en que defiende la naturaleza frente a la opresión humana. Empieza como tareas limitadas al mundo mágico, fuera de la vista de su padrastro, pero con cada prueba su resistencia se acerca más al mundo real y al capitán.

Se alude a la tensión entre Ofelia y su padrastro desde el principio del filme cuando se destaca la obsesión que éste tiene por la tecnología, la disciplina y la puntualidad ${ }^{16}$. Además de su yuxtaposición con su reloj, coloca su oficina al lado de la maquinaria ya inmóvil del molino de la casa y las giras de éste figuran prominentemente al fondo de varias tomas. El capitán también pone música en un gramófono cada vez que se afeita; del Toro emplea ángulos picados que capturan el disco mientras gira y panea por todo el cuarto antes de terminar estas secuencias en el espejo. A diferencia del brutal capitán fascista, Ofelia (y los maquis) prefiere(n) la naturaleza, una entidad que el capitán fascista jamás entenderá. Se alude a la alianza entre Ofelia y la naturaleza desde los primeros momentos del filme, cuando encuentra un hada en forma de insecto. Luego, durante su primera noche en la casa, el hada regresa; cuando la niña le muestra la imagen de un hada de forma humanoide en su libro, esta criatura toma forma femenina con alitas de hoja. Aquí del Toro se distancia de las técnicas hollywoodenses de imaginar las hadas como pequeños seres humanos (Tsuei 232), pues aunque tomen una forma (más) humana, mantienen su conexión a la naturaleza y a la flora natural. El hada la lleva al fauno, quien empieza como estatua de piedra, cubierta por flores y hierba. Cuando el hada lo despierta, éste le cuenta a Ofelia que ella es la princesa Moanna, y que su padre en un mundo eterno subterráneo lleva años buscándola. Para comprobar que su esencia inmortal todavía permanece, la joven debe enfrentar tres desafíos, los cuales se encontrarán en un libro que el fauno le otorgará. Estas tareas requieren que ella se alíe con la naturaleza frente al fascismo y/o el consumismo desenfrenado.

En su primer desafío, Ofelia tiene que salvar un árbol de un sapo enorme que vive entre sus raíces. Según Thomas Deveny, aunque se enfrenta a un monstruo, este primer desafío es sobre todo una prueba interna en su

15 Kam Hei Tsuei interpreta el fauno como un monstruo "anti-fascista" (230).

16 Según Cecilia Enjuto Rangel, el director, al proponer "una estética trans-Atlantica, [. . .] sugiere además una reapropiación de las hadas", pues muchos escritores fascistas reclamaban la literatura para ellos. 
búsqueda heroica campbelliana, pues Ofelia tiene que creer en su herencia como princesa y confiar en su alianza con la magia y la naturaleza ("Once Upon" 7). Como lee la niña:

Al principio de los tiempos, cuando el bosque era joven, vivían en harmonía los hombres y las criaturas mágicas. Se protegían los unos a los otros, y dormían juntos bajo la sombra de un frondoso árbol que crece en la colina cerca del molino. Ahora el árbol se muere, sus ramas están secas, su tronco viejo y torcido. Debajo de sus raíces ha anidado un enorme sapo que no le deja sanar.

Julià María Labrado Ben arguye que el sapo representa al capitán. Llega a esta interpretación porque entiende el mundo fantástico como una creación de la imaginación de Ofelia; como tal, cualquier ente malo es una construcción freudiana de su padrastro. Además de las conexiones innegables entre el sapo y Vidal, argüimos que esta escena critica el consumismo, un impulso que perjudica el medio ambiente y a los seres humanos; como tal, este anfibio representa los vicios no sólo del capitán sino los de Ofelia. Es interesante que el ser destructivo sea un sapo, pues normalmente damos por entendido que ningún animal (con la excepción del ser humano o una especia desplazada) puede perjudicar el medioambiente, pues son partícipes en un sistema ecológico. Ahora bien, este sapo es un monstruo mágico que parece tener cierto conocimiento de sus acciones, lo cual lo asemeja más al ser humano. Al consumir los insectos y destruir el árbol actúa de una manera egoísta y opresiva. Ofelia lo elimina al tentarle con varios bichos impregnados de piedras mágicas, las cuales provocan que el sapo vomite sus tripas y muera cuando los come. Al cumplir su tarea, Ofelia recoge una llave entre sus entrañas y vuelve a casa ${ }^{17}$.

La secuencia con el sapo no se representa consecutivamente; más bien es parte de un montaje paralelo que también sigue al capitán Vidal en una de las primeras pesquisas que hace en el filme. Ve humo en las montañas y va con varios subordinados a investigar. Encuentran un campamento republicano y el capitán lamenta "ellos conocen el terreno mejor que nadie". Podemos tomar estas palabras literalmente, pero en un nivel más simbólico, el militar alude al hecho que los rebeldes tienen una relación más estrecha con la naturaleza que él. La ventaja de los maquis no es solamente estratégica, sino cualitativa, pues viven (y resisten) según una modalidad ilegible para el capitán. En esta excursión no encuentran a nadie, pero el capitán halla un frasco de antibiótico sellado. Este descubrimiento tiene mucha

17 Brígida M. Pastor arguye que el acto de Ofelia de destripar al sapo paralela la escena en que Mercedes le corta el cachete al capitán (396). 
importancia discursiva porque la medicina es un producto de la sociedad tecnológica y científica. Vidal recobra su ánimo y, antes de desistir, levanta el frasco, gritándoles a los republicanos, quienes lo oyen aunque él no los vea, "¡os habéis olvidado esto!" Aquí el capitán asevera el monopolio que tiene sobre la medicina y la tecnología en general. Reconoce que no tiene la ventaja si se pelean en el monte, pero también sabe que a fin de cuentas lo que más importa es el acceso a la medicina, la industria y bases fortalecidas (Hubner 48). Del Toro artísticamente asevera la alianza entre la ecología y la resistencia política cuando los falangistas se van. El director panea a los maquis, quienes emergen del bosque en una toma de ángulo contrapicado que captura tanto a ellos como al polen que vuela al fondo. Las cortes paralelas entre esta secuencia y la de Ofelia con el sapo aluden a las diferentes modalidades de estos antagonistas de experimentar y negociar el mundo. Mientras avanza la película, la tensión entre Ofelia y su padrastro aumenta, y sus historias convergen.

La segunda prueba alude al enfrentamiento que la joven protagonista pronto tendrá con Vidal. Ofelia utiliza una tiza mágica para entrar a un salón de comidas y ve una mesa llena de comida que se asemeja a la mesa de su padrastro en una toma anterior (Tierney 176-78; Smith 8; Sisk 23940; Ramos; O'Flynn; Deaver 160). Del Toro emplea tomas de profundidad de foco para que veamos tanto el banquete como el inquietante Hombre Pálido - uno de los monstruos más memorables del cine de del Toro- que se sienta al fondo de la mesa enfrente de una fogata ${ }^{18}$. Según Tierney, "the Pale Man appears as a displaced version of Vidal with a number of textual parallels suggesting this connection where physical appearance does not" (178), así señalando una tendencia fascista en partes del mundo fantástico también. Tanto el fauno como su libro mágico le recuerdan que no debe comer ni beber nada en el salón del Hombre Pálido, pero titubea cuando entra y come dos uvas. El papel de la naturaleza es menos obvia aquí que en cualquier otra escena mágica del filme, pero existe como una extensión lógica de su encuentro con el sapo, pues aquí Ofelia debe dominar sus propios instintos consumistas. Según Hubner, la desobediencia de Ofelia le da poder frente al patriarcado (56-57), pues mayormente resiste cuando no le parece justo lo que se le manda ${ }^{19}$. Debemos calificar su análisis en esta escena porque su desobediencia resulta en la muerte de dos hadas a quienes come el Hombre Pálido cuando se despierta.

18 Muchos críticos han escrito sobre este monstruo y su conexión al fascismo e infanticida. Véase Spector (83); Kristine Kotecki (245); Deveny (3, 7).

19 Julià María Labrador Ben contrasta la desobediencia de Ofelia con la obediencia ciega del capitán (425-28). 
Esta escena recrea el mito de Eva, pues Ofelia falla al cederse a la tentación de consumir el fruto prohibido (Lindsay 18) ${ }^{20}$. Tal como este pecado original coincidió con la expulsión de Eva del jardín mágico de Edén, las acciones de Ofelia la alejan del mundo mágico del fauno, quien le dice que jamás podrá volver con su padre. El fracaso de Ofelia también perjudica la salud de su madre en el mundo real. En un momento anterior entre las primeras dos pruebas, Carmen sufre complicaciones de embarazo y tiene que guardar cama. Ofelia y su padrastro intentan cuidarla de maneras inconmensurables, pues el capitán se aferra a la medicina y tecnología y Ofelia a la magia. El militar encomienda a su esposa al doctor, ordenándole que la cuide bien, pero le ordena que salve primero al hijo. A pesar de sus mayores esfuerzos, el doctor no puede contener la enfermedad y Carmen empeora. Cuando llega el fauno para felicitarle su primer logro, Ofelia le dice que no puede enfocarse en sus deberes ya que su madre está mal. El fauno le brinda una mandrágora - una raíz antropomórfica que varias culturas han imbuido con propiedades restaurativas (Shaw 81 83; Thormann 178-79) - que debe poner debajo de la cama de su madre, donde sanará a Carmen al alimentarse con su sangre. La evidencia fílmica postula el mejoramiento de Carmen como resultado de las acciones de Ofelia, pues sólo empieza a recuperarse cuando su hija pone la raíz debajo de su cama. Hablando de su mejor condición, el doctor dice, "no me lo explico, pero me alegro". El capitán no ve estas pruebas de la magia -y aunque las viera seguramente las rechazaría - y en vez de atribuir el milagroso cambio en la salud de Carmen a la naturaleza (mucho menos la magia), se lo asigna a la ciencia, la medicina y la buena fortuna. Sin embargo, cuando el fauno se entera de las desventuras de Ofelia con el Hombre Pálido, la mandrágora deja de sanar a Carmen.

Al ceder ante sus deseos de consumir, Ofelia ha perdido la esencia que antes la aliaba con la magia y la naturaleza. Arrepentida, regresa a la recámara de su madre y alimenta a la mandrágora nuevamente con la sangre de Carmen, pero el capitán la pilla, reacciona violentamente, y la regaña por haber perjudicado la salud de su madre. Al oler la raíz atestigua su hedor, y cuando Ofelia explica que es mágica, éste le dice a Carmen "esto es por la mierda que tú la dejas leer". Por un lado, las acciones de Vidal parecen las de cualquier adulto, pues la raíz no es sanitaria y la idea que pudiera sanar a una mujer embarazada es ridícula. Sin embargo, a

20 Para Antonio Gómez López Quiñones, Ofelia come la uva porque también sufre el hambre de los maquis; es más no fracasa porque se escapa con vida. 
otro nivel afirma las formas irreconciliables de ver y experimentar el mundo de la niña y su padrastro. En gran parte, el antagonismo entre los dos gira sobre el hecho que sus experiencias contradictorias han imposibilitado la comunicación entre ellos. No obstante, del Toro le asigna la mayor parte de la culpa de esta falta de comprensión al capitán Vidal, pues como vemos durante toda la película, Ofelia no ve la magia y la ciencia en oposición binaria. Nunca se ha opuesto a la presencia del doctor con su madre a pesar de atribuir su sanación a la mandrágora. Así que, aunque se alía con la naturaleza, Ofelia aboga por un mundo en que ambas formas de saber existan.

Además de insultar a Ofelia por su imaginación, el capitán obliga a los demás - especialmente a su esposa-a adoptar su forma de ver el mundo. En un acto que Kristine Kotecki ve como su capitulación al patriarcado (244), Carmen se ofrece como intermediaria, prometiéndole al capitán que ella misma se encargará de su hija ${ }^{21}$. Vidal le deja la raíz, y ésta la echa al fuego para mostrarle a Ofelia que la magia no existe. Momentos después, Carmen se cae al piso y empieza una mortal labor de parto. Varios críticos arguyen que Carmen muere porque rechaza el mundo fantástico (Deveny 4; Kotecki 244; Orme 227), pero el filme es más ambivalente. Es cierto que Ofelia atribuye la muerte de su madre en gran medida a que no dejaron que la raíz obrase su magia, pero los adultos la ven como un resultado esperado después de un embarazo difícil. Todo el filme destaca esta ambigüedad, dándonos algunas razones para creer que la magia que Ofelia ve es mera imaginación y otras que afirman que las fantasías que reporta son verdaderas (Lukasiewicz 63) ${ }^{22}$. Es solamente a través de las pistas intratextuales en otros filmes como Hellboy II: The Golden Army -donde aparecen las hadas de El laberinto del fauno (Hutchings 91-92) - que podemos hallar evidencia convincente acerca de la veracidad de sus visio-

21 Esta observación es más acertada aún cuando tomamos en cuenta la observación de Silvanna Mandeolessi y Emmy Poppe de que el patriarcado es un síntoma fuerte del fascismo (25-26).

22 La crítica está dividida en su recepción del mundo fantástico que habita Ofelia. Algunos piensan que "the magic that Ofelia encounters is as real as the violence the captain commits" (Orme 226; véase también Vargas 190; Shaw 86-87), otros creen que imagina todo (Hubner 50; Labrado Ben 421-25; Smith 6; Sánchez 138; Thormann 175-78). Todavía otros ven estos mundos paralelos paradójicamente y ambiguamente reales (Hanley 39; Lukasiewicz 68-69). Siobhan O'Flynn, por ejemplo, asevera "the reality of the secondary [magic] world as a realm that can be accessed from the primary world". Todavía otros arguyen que es una ficción verídica (Deveny 2; Richstatter 78). 
nes $^{23}$. La ambigüedad entre lo real y lo fantástico es de suma importancia en el desarrollo del filme, pues con la posible excepción de Ofelia, nadie puede saber con certeza si el mundo mágico de la película existe o no. El tercer desafío de Ofelia sirve también como su última confrontación con el capitán. En esta secuencia ambos se aferran a sus discursos preferidos (la ciencia y tecnología en el caso del militar, la magia en el caso de la niña), $y$ ambos creen ganar.

Con la muerte de su madre Ofelia decide escaparse del capitán Vidal. Como piensa que ya ha sido expulsada del mundo fantástico del fauno, intenta huir con Mercedes - una sirvienta de Vidal e informante maqui- a las montañas. El capitán las captura y encierra a Ofelia en su dormitorio, ordenando a los militares que la fusilen si trata de salir. Es en este punto que los dos mundos convergen; el fauno aparece en el cuarto de la niña y le ordena que use la tiza mágica para escaparse y traerle su hermano al centro del laberinto. Lukasiewicz nota que la única manera en que Ofelia pudiera salir de su cuarto sería por un conducto mágico (69), pero el filme no hace hincapié en esto, más bien los personajes reaccionan al hecho que se escapó sin preguntarse cómo. Ofelia envenena a su padrastro y se escapa, y éste la persigue torpemente. Del Toro enfatiza que los adultos jamás comprenderán el mundo fantástico de Ofelia cuando Vidal entra al cuarto de la niña, y aunque él no la percibe, la audiencia ve la puerta que dibujó Ofelia. Puede que el capitán no reconozca el papel de la magia ni el potencial redentor de la naturaleza, pero los espectadores omniscientes perciben y entienden los elementos de este puesto en escena.

La magia y la naturaleza colaboran en ayudar a Ofelia a entrar al centro del laberinto antes de su padrastro, pues las paredes se abren, dándole paso directo. Anne Davies arguye que "the labyrinth of the film is [. . .] the path between the two dimensions and a part of both" (40). Visto de esta manera, no es sorprendente que la última confrontación suceda aquí; una de las razonas por las que este laberinto habita en ambos mundos son sus conexiones a la ecología. El camino se dirige hacia un jardín, y el papel resistente de la flora mágica se destaca fílmicamente cuando el muro se abre y luego cuando se cierra. Los muros están hechos de piedra, pero el elemento más visual son las raíces que viven por dentro que mueven las piedras de un lado a otro. En cuanto la joven pasa por allí, los muros se

23 La oposición entre la tecnología y la naturaleza es un tema común en la obra de del Toro, pero es más obvia en Hellboy II: The Golden Army (Podalsky 101-02; 115-17), película que existe en el mismo "universo imaginativo" (Shaw 4). 
cierran, así demorando el paso del padrastro. Ésta es la primera escena en que la magia y la naturaleza intervienen directamente en los asuntos políticos del mundo real. Ofelia pronto llega al centro del laberinto y encuentra al fauno, quien le dice que tendrá que derramar una gotita de sangre de su hermano para entrar al reino de su padre. Vidal llega cuando Ofelia se rehúsa, le quita el niño, la dispara y la deja muriéndose en el altar del jardín. Irónicamente, el capitán facilita que Ofelia regrese con su familia en el mundo subterráneo cuando derrama su sangre inocente. La magia también tiene un sentido de justicia, pues el laberinto lleva al capitán directamente a los maquis, quienes lo ejecutan.

Cuando los maquis llegan al centro del laberinto, hallan a Ofelia moribunda. La cámara panea a la derecha y las tonalidades toman un color de oro (ostensiblemente por el fuego que ahora consume lo que antes fue la casa del capitán) reflejado en polen que flota en el aire. Luego del Toro corta al castillo de los padres de Ofelia en el mundo mágico. Empieza con una toma de ángulo picado de sus zapatos rojos en el piso, una referencia intertextual a The Wizard of $\mathrm{Oz}$ que afirma que la princesa ha vuelto a su hogar. Corta nuevamente al mundo real con sus tonalidades oscuras, y Ofelia muere con una sonrisa. No obstante, en la última toma el narrador omnisciente relata que la princesa Moanna todavía habita el mundo real si uno sabe en dónde buscarla. El filme cierra con una toma de una flor que abre en el árbol que Ofelia rescató del sapo. Esta secuencia de cortes juega un papel clave en establecer la naturaleza como una entidad resistente al totalitarismo, pues cada toma que sugiere que sigue viva invoca a la ecología.

El hecho que la naturaleza funciona como ente mágico y resistente que une la familia (tradicional y patriarcal) tanto en El laberinto como en Bivtiful es especialmente interesante ya que estos filmes son tan diferentes. Como coproducciones transnacionales, tanto mexicanas como españolas, estas películas encarnan ciertas tendencias culturales de ambos países. Las circunstancias de su producción cuestionan la validez de invocar un cine nacional en un mundo cada vez más globalizado (Shaw 78-83), pero la nacionalidad del director sigue influyendo el empeño de un texto fílmico. Tal vez uno de los legados más importantes de El laberinto y Biutiful es que ambas películas señalan estrategias para proyectar ideas locales a Europa de una manera universalista que atrae un público más amplio. Al basarse en imaginarios latinoamericanos para teorizar maneras de resistir la opresión en un país como España, estos directores enfatizan la necesidad de dialogar para poder enfrentar los desafíos que nos rodean. Una contribución inesperada de ambos directores mexicanos es la exaltación del retorno a la naturaleza, una entidad que lleva el potencial resistente necesario para articular una vida auténtica en un mundo opresivo. 


\section{Bibliografía}

BEGIN, Paul. "Empathy and Sinophobia: Depicting Chinese Migration in Biutiful (Inárritu, 2010)." Transnational Cinemas 6.1 (2015): 1-16. Taylor \& Francis. Web. 12 de nov, 2015.

CAMINO, Mercedes. "Blood of and Innocent: Montxo Armendáriz's Silencio Roto (2011) and Guillermo del Toro's El laberinto del fauno (2006)." Studies in Hispanic Cinemas 6.1 (2009): 45-64. Impreso.

CARRASCO, Cristina. "Contestatory Fairy Tales and Liminal Spaces in Guillermo del Toro's Pan's Labyrinth." Revista de Humanidades: Tecnológico de Monterrey 31-32 (2011; 2012): 13-30. cervantesvirtual.com. Web. 2 de dic, 2015.

CASAS AGUILAR, Anna. "Espectros de la paternidad y disolución de fronteras en Biutiful de Alejandro González Iñárritu." Journal of Spanish Cultural Studies (2015): 179-91. Taylor \& Francis. Web. 20 de oct, 2015.

CLARK, Roger y Keith MCDONALD. "'A Constant Transit of Finding': Fantasy as Realisation in Pan's Labyrinth." Children's Literature in Education 41 (2010): 52-63. ebsco. Web. 12 de nov 2015.

CHÁVEZ, Daniel. "De faunos hispánicos y monstruos en inglés, la imaginación orgánica de Guillermo del Toro." Tendencias del cine iberoamericano en el nuevo milenio: Argentina, Brasil, España y México. Ed. Juan Carlos Vargas. Guadalajara: U de Guadalajara, 2011. Impreso.

DAVIES, Anne. "Guillermo del Toro's Monsters: Matter out of Place." The Transnational Fantasies of Guillermo del Toro. Ed. Ann Davies, Deborah Shaw y Dolores Tierney. Nueva York: Palgrave Macmillan, 2015. 29-44. Impreso.

DEAVER JR., William O. "El laberinto del fauno: Una alegoría para la España democrática." Romance Notes 49.2 (2009): 137-46. Academic OneFile. Web. 4 de dic, 2015.

DEL MAR AZCONA, María. "We Are All Uxbal: Narrative Complexity in the Urban Borderlands in Biutiful." Journal of Film and Video 61.1 (2015): 3-13. Project Muse. Web. 20 de nov, 2015.

DEL TORO, Guillermo, dir. El espinazo del diablo. Perf. Marisa Paredes, Eduardo Noriega y Federico Luppi. El deseo, Tequila Gang, Sogepaq, 2001. DVD.

-. El laberinto del fauno. Perf. Sergi López, Maribel Verdú, Ivana Baquero, Doug Jones, Ariadna Gil y Alex Ángulo. Estudios Picasso, Tequila Gang, Esperanto Filmoj, 2006. DVD.

-. Hellboy II: The Golden Army. Perf. Ron Pearlman, Selma Blair y Doug Jones. Universal Pictures, 2008. DVD. 
-. "The Power of Myth." Pan's Labyrinth, disco 2. Optimum House Entertainment, 2006. DVD.

DELEYTO, Celestino y Gemma López. "Catalan Beauty and the Transnational Beast: Barcelona on the Screen." Transnational Cinemas 3.2 (2012): 157-75. Taylor \& Francis. Web. 10 de nov, 2015.

DELEYTO, Celestino y María del Mar Azcona. Alejandro González Iñárritu. Urbana: U of Illinois P, 2010. Impreso.

DEVENY, Thomas. "Once Upon a Time in Spain in 1944: The Morphology of El laberinto del fauno." tdl.org. Web. 12 de nov, 2015.

-. Migration in Contemporary Hispanic Cinema. Lanham: Scarecrow P, 2012. Impreso.

DIFRANCESCO, María. "Facing the Specter of Immigration in Biutiful." Symposium 69.1 (2015): 25-37. West Chester University Libraries. Web. 27 de oct, 2015.

ENJUTO RANGEL, Cecilia. "La Guerra Civil Española: Entre fantasmas, faunos y hadas." Vanderbilt e-Journal of Luso-Hispanic Studies 5 (2009): sin paginación. Web. 2 de noviembre, 2015.

FRASER, Benjamin. "A Biutiful City: Alejandro González Iñárritu's filmic critique of the 'Barcelona Model.'" Studies in Hispanic Cinemas 9.1 (2012): 19-34. Impreso.

GIUNTINI, Mauro. "A narrativa cinematográfica de Alejandro González Iñárritu." Tesis: U de Brasília, 2015. repositorio.unb.br. Web. 10 de nov, 2015.

GÓMEZ-CASTELLANO, Irene. "Lullabies and Postmemory: Hearing the Ghosts of Spanish History in Guillermo del Toro's Pan's Labyrinth (El laberinto del fauno, 2006)." Journal of Spanish Cultural Studies 14.1 (2013): 1-18. Taylor \& Francis. Web. 2 de nov, 2015.

GONZÁlEZ IÑÁRRITU, Alejandro, dir. Biutiful. Perf. Javier Bardem. Menageatroz, Mod Producciones, Focus Features, 2010. DVD.

HANLEY, Jane. "The Walls Fall Down: Fantasy and Power in El laberinto del fauno." Studies in Hispanic Cinemas 4.1 (2007): 35-45. Impreso.

HING-YUK WONG, Cindy. "'The Chinese Who Never Die': Spectral Chinese and Contemporary European Cinema." Asian Cinema 23.1 (2012): 5-29. Impreso.

HUBNER, Laura. "Pan's Labyrinth, Fear, and the Fairytale." Fear Itself: Reasoning the Unreasonable. Ed. Stephen Hessel and Michèle Huppert. Amsterdam: Rodopi, 2010. 45-62. Impreso.

HUTCHINGS, Peter. "Adapt or Die: Mimicry and Evolution in Guillermo del 
Toro's English-Language Films." The Transnational Fantasies of Guillermo del Toro. Ed. Ann Davies, Deborah Shaw y Dolores Tierney. Nueva York: Palgrave Macmillan, 2015. 83-97. Impreso.

KOTECKI, Kristine. "Approximating the Hypertextual, Replicating the Metafictional: Textual and Sociopolitical Authority in Guillermo del Toro's Pan's Labyrinth." Marvels \& Tales 24.2 (2010): 235-54. Project Muse. Web. 2 de nov, 2015.

LABRADOR BEN, Julià María. "La maldad genera cuentos de hadas: Análisis de la película de Guillermo del Toro El laberinto del fauno." ARBOR Ciencia, Pensamiento y Cultura (marzo-abril 2011): 421-28. Web. 2 de nov, 2015.

LÓPEZ-QUIÑONES, Antonio Gómez. "Hadas, maquis y niños sin escuela: La infancia romántica y la guerra civil en El laberinto del fauno." Vanderbilt e-Journal of Luso-Hispanic Studies 5 (2009): sin paginación. Web. 2 de noviembre, 2015.

LUKASIEWICZ, Tracie D. "The Parallelism of the Fantastic and the Real: Guillero del Toro's Pan's Labyrinth/El laberinto del fauno and Neomagical Realism." Fairy Tale Films Ed. Pauline Greenhill and Sidney Eve Matrix. Logan: Utah State UP, 2010.60-78. DigitalCommons@USU. Web. 12 de nov, 2015.

MANDOLESSI, Silvana y Emmy Poppe. "Dos estéticas de lo sobrenatural: lo siniestro en El espinazo del diablo y lo abyecto en El laberinto del fauno de Guillermo del Toro." Confluencia 27.1 (2011): 16-32. JSTOR. Web. 13 de nov, 2015.

MILES, Robert J. "Reclaiming Revelation: Pan's Labyrinth and The Spirit of the Beehive." Quarterly Review of Film and Video 28 (2011): 195-203. Taylor \& Francis. Web. 23 de oct, 2015.

LINDSAY, Richard. "Menstruation as Heroine's Journey in Pan's Labyrinth." Journal of Religion and Film 16.1 (2012): 1-27. DigitalCommons@UNO. Web. 13 de nov, 2015.

O'FLYNN, Siobhan. "The Fragility of Faith in the Films of Guillermo del Toro." 1-26. academia.edu. Web. 13 de nov, 2015.

ORELLANA GUTIÉRREZ DE TERÁN, Juan. "Las mixtificaciones narrativas en el cine de Alejandro González Iñárritu." Revista Comunicación 10.1 (2012): 1157-71. unirioja.es. Web. 12 de nov, 2015.

ORME, Jennifer. "Narrative Desire and Disobedience in Pan's Labyrinth." Marvels \& Tales: Journal of Fairy-Tale Studies 24.2 (2010): 219-34. ProQuest. Web. 13 de nov, 2015.

PASTOR, Brígida M. "La bella y la bestia en el cine laberíntico de Guillermo 
del Toro: El epinazo del diablo (2001) y El laberinto del fauno (2006)." ARBOR Ciencia, Pensamiento y Cultura (marzo-abril 2011): 391-400. Web. 2 de nov, 2015.

PODALSKY, Laura. "Of Monstrous Masses and Hybrid Heroes: Del Toro's English-Language Films." The Transnational Fantasies of Guillermo del Toro. Ed. Ann Davies, Deborah Shaw y Dolores Tierney. Nueva York: Palgrave Macmillan, 2015. 99-120. Impreso.

RAMOS, Yvonne Gavela. "El acto colectivo de recordar: Historia y fantasía en El espíritu de la colmena y El laberinto del fauno." Bulletin of Hispanic Studies 88.2 (2011): 179-96. ProQuest. Web. 13 de nov, 2015.

RICHSTATTER, Katje. "Two Dystopian Movies... and their Visions of Hope." Tikkun 22.2 (marzo/abril 2007): 78-79. ProQuest. Web. 13 de nov, 2015. RIVERA-BARNES, Beatriz y Jerry Hoeg. Reading and Writing the Latin American Landscape. Nueva York: Palgrave Macmillan, 2009. Impreso.

Sánchez, Franciso J. "A Post-National Spanish Imaginary: A Case Study: Pan's Labyrinth."

SÁNCHEZ PRADO, Ignacio. "Amores perros: Exotic Violence and Neoliberal Fear." Journal of Latin American Cultural Studies 15.1 (2006): 39-57. Impreso.

-. Screening Neoliberalism: Transforming Mexican Cinema 1988-2012. Nashville: Vanderbilt UP, 2014. Kindle. Web. 9 de julio, 2014.

SANTAOLALLA, Isabel. Los "Otros": etnicidad y "raza" en el cine español contemporáneo. Zaragoza: P U de Zaragoza, 2005. Impreso.

SHAW, Deborah. The Three Amigos: The Transnational Filmmaking of Guillermo del Toro, Alejandro González Iñárritu, and Alfonso Cuarón. Manchester: Manchester UP, 2013. Impreso.

SISK, Cristina. "Entre el Cha Cha Chá y el Estado: El cine nacional mexicano y sus arquetipos." A Contra Corriente 8.3 (primavera 2011): 163-82. ncsu.edu. Web. 13 de nov, 2015.

SMITH, Paul Juliàn. Pan's Labyrinth (El laberinto del fauno). Film Quarterly 60.4 (verano 2007): 4-9. JSTOR. Web. 16 de oct, 2015.

SPECTOR, Barry. "Sacrifice of the Children in Pan's Labyrinth." Jung Journal: Culture \& Psyche 3.1 (verano 2009): 81-86. Taylor \& Francis. Web. 12 de nov, 2015.

THORMANN, Janet. "Other Pasts: Family Romances of Pan's Labyrinth." Psychoanalysis, Culture \& Society 13 (2008): 175-87. ProQuest. Web. 4 de dic, 2015. 
TIERNEY, Dolores. "Transnational Political Horror in Cronos (1993), El espinazo del diablo (2001), and El laberinto del fauno (2006)." The Transnational Fantasies of Guillermo del Toro. Ed. Ann Davies, Deborah Shaw y Dolores Tierney. Nueva York: Palgrave Macmillan, 2015. 161-82. Impreso. -, Deborah Shaw y Anne Davies. "Introduction." The Transnational Fantasies of Guillermo del Toro. Ed. Ann Davies, Deborah Shaw y Dolores Tierney. Nueva York: Palgrave Macmillan, 2015. 1-10. Impreso.

TORRES-HORTELANO, Lorenzo J. "De lo vernacular y el world cinema en Biutiful." Revista de Comunicación de la SEECl 15.24 (marzo 2011): 5058. unirioja.es. Web. 23 de oct, 2015.

TSUEI, Kam Hei. "The Antifascist Aesthetics of Pan's Labyrinth." Socialism and Democracy 22.2 (2008): 225-44. Taylor \& Francis. Web. 20 de oct, 2015.

VARGAS, Juan Carlos. "Between Fantasy and Reality: The Child's Vision and Fairy Tales in Guillermo del Toro's Hispanic Trilogy." The Transnational Fantasies of Guillermo del Toro. Ed. Ann Davies, Deborah Shaw y Dolores Tierney. Nueva York: Palgrave Macmillan, 2015. 183-98. Impreso. 